\title{
"Frictions in Financial and Labor Markets": A Summary of the 35th Annual Economic Policy Conference
}

\author{
Rodolfo Manuelli and Adrian Peralta-Alva
}

\begin{abstract}
This article contains synopses of the papers presented at the 35th Annual Economic Policy Conference of the Federal Reserve Bank of St. Louis held October 21-22, 2010. The conference theme was "Frictions in Financial and Labor Markets." Leading participants in this field presented their research and commentary.
\end{abstract}

Federal Reserve Bank of St. Louis Review, July/August 2011, 93(4), pp. 273-92.

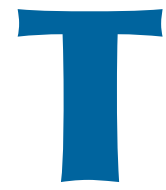

he Thirty-Fifth Annual Economic Policy Conference of the Federal Reserve Bank of St. Louis was held October 21-22, 2010. The papers presented at the conference covered a variety of approaches and topics within the general theme of frictions in financial and labor markets. One group of papers directly addresses the question of the impact of frictions in financial markets-defined as a departure from the complete market, perfectly competitive Arrow-Debreu equilibrium-on economic performance. In "Quantifying the Impact of Financial Development on Economic Development," Greenwood, Sanchez, and Wang study the impact of increases in the relative (to the rest of the economy) efficiency of financial intermediaries in output and total factor productivity (TFP). For a calibrated version of their model they conclude that financial frictions can account for large changes in output and measured TFP. A somewhat different conclusion is reached by Midrigan and Xu in "Finance and Misallocation: Evidence from Plant-Level Data." In that paper, the authors study a different financial friction- a borrowing limit—and find that when the model must match the observed distribution of the growth rate of the output of individual firms, the contribution of market imperfections to TFP is rather small.

In "Middlemen in Limit-Order Markets," Jovanovic and Menkveld analyze the role of middlemen in asset markets who are assumed to have superior information and, hence, potentially improve the allocation of resources as they can "direct" each asset to its best use. They find that, depending on the distribution of information of potential asset traders, the presence of middlemen can either increase or decrease efficiency. They also confront the model with data that are consistent with the introduction of middlemen but their results are ambiguous. The last paper that most directly discusses the role of financial frictions is "Financial Markets and Unemployment," by Monacelli, Quadrini, and Trigari. They study a situation in which firms and workers bargain for wages but the total surplus-the object to be divided-decreases in relation to the amount of debt carried by the firm. They show that, in

Rodolfo Manuelli is a professor and director of graduate studies in the department of economics at Washington University in St. Louis and a visiting scholar at the Federal Reserve Bank of St. Louis. Adrian Peralta-Alva is a senior economist at the Federal Reserve Bank of St. Louis. Author-provided papers delivered at the conference can be found at http://research.stlouisfed.org/conferences/policyconf/35program.html.

(C) 2011, The Federal Reserve Bank of St. Louis. The views expressed in this article are those of the author(s) and do not necessarily reflect the views of the Federal Reserve System, the Board of Governors, or the regional Federal Reserve Banks. Articles may be reprinted, reproduced, published, distributed, displayed, and transmitted in their entirety if copyright notice, author name(s), and full citation are included. Abstracts, synopses, and other derivative works may be made only with prior written permission of the Federal Reserve Bank of St. Louis. 
response to a positive productivity shock, firms will choose to borrow more since this lowers their current surplus and thus the wage demands of their workers.

A second set of papers looks at the role of search frictions in labor and goods markets. In "Joint-Search Theory: New Opportunities and New Frictions," Guler, Guvenen, and Violante consider the employment-search problem of a couple. They show that, in the absence of a market that permits perfect risk-sharing, location decisions and employment decisions are related and, due to the costs of separation from one's partner, some workers would reject job offers that appear to be above their reservation wage. A similar idea-searching for a price in this case-drives the price dispersion results in "Equilibrium Price Dispersion and Rigidity: A New Monetarist Approach," by Head, Liu, Menzio, and Wright. They show that when individuals differ in their ability to search for the lowest price, (i) the optimal pricing policy of a firm involves periods of price stickiness (when average prices are changing) and (ii) price dispersion may occur in equilibrium even when there is no inflation.

Finally, two papers deal with the effect of frictions on income distribution. In "Intergenerational Redistribution in the Great Recession," Glover, Heathcote, Krueger, and Ríos-Rull study how a recession-not unlike the recent one in the United States-influences the welfare of different generations. They show that (i) asset prices will likely fall more than warranted by fundamentals and (ii) this has a negative effect on relatively older households. At the other end of the spectrum, younger households see their labor income drop but are able to purchase some assets (from the older generations) at bargain prices. Their welfare does not decrease as much as that of the older cohorts and, in some cases, it may increase. In "Social Security, Benefit Claiming, and Labor Force Participation: A Quantitative General Equilibrium Approach," İmrohoroğlu and Kitao consider the quantitative implications of three alternative Social Security reforms: reductions in benefits, increases in normal retirement age, and increases in the earliest retirement age. They find that these proposals will have long-run posi- tive effects. Even though this is not the focus of their paper, it seems that such changes could hurt current retirees and individuals close to retirement.

Overall, the research at the conference succeeded in focusing attention of academic economists and policymakers alike on the role of frictions in the economy.

\section{INDIVIDUAL CONTRIBUTIONS}

In the following sections we briefly describe the essential elements of the individual conference papers. The aim is not to provide a complete description of the environment and results, but rather to convey the major methodological and factual contributions of the research. In some cases, our analysis goes beyond the conference version of the paper and tries to draw inferences relevant for policymakers.

\section{QUANTIFYING THE IMPACT OF FINANCIAL DEVELOPMENT ON ECONOMIC DEVELOPMENT}

How do changes in the productivity of the financial intermediary sector affect the level of output? This is the question studied by Greenwood, Sanchez, and Wang. In their model, financial intermediaries exist because they better detect misreporting by firms.

The main theoretical finding is that increases in the efficiency of financial intermediaries (relative to the rest of the economy) increase output through two channels. First, the set of firms that receive funding shrinks and includes more highproductivity firms. Second, the size of the loan that each firm receives-which in all cases falls short of the perfect information level-increases for the most-productive firms and decreases for the least-productive.

Greenwood, Sanchez, and Wang calibrate their model to match the relevant data for the United States and use it to predict the impact on a given country's output level if it adopted Luxembourg's financial system. The basic model does an excellent job matching the cross-country 
evidence and suggests that large gains are possible with efficiency-increasing developments in the financial intermediary sector.

\section{The Model}

The production function of a firm is given by

$$
y=x \theta k^{\alpha} \ell^{1-\alpha},
$$

where $x$ is an aggregate productivity shock (common to all firms), $\theta$ (which can take two values $\theta_{1}<\theta_{2}$ ) is a firm-specific shock, and $k$ and $\ell$ are, respectively, capital and labor. The key assumption is that although the type of firm is public knowledge (i.e., the set $\tau=\left(\theta_{1}, \theta_{2}\right)$ is known), the particular realization of $\theta$ is not.

Since firms need to borrow funds to purchase capital, they contract with a financial intermediary. The distinguishing feature of this intermediary is its access to a monitoring technology. Greenwood, Sanchez, and Wang describe the properties of this monitoring technology in terms of the probability of detecting a cheater-a firm that claims to have received a low-productivity draw, $\theta_{1}$, when in fact it enjoys high productivity, $\theta_{2}$-as a function

$$
P_{i j}\left(\ell_{m j}, k, z\right),
$$

where $P_{i j}\left(\ell_{m j}, k, z\right)$ is the probability of detecting fraud when a firm announces that its productivity is $\theta_{j}$ when in fact it is $\theta_{i}$. This probability increases the number of workers assigned to monitoring, $\ell_{m j}$, as well as the productivity of the financial sector, $z$. It decreases with the size of the loan, capturing the idea that larger (and more complex) loans are more difficult to monitor.

Greenwood, Sanchez, and Wang analyze the optimal contract between financial intermediaries and firms. They find that

(i) the set of projects that is financed-that is, the set of $\tau=\left(\theta_{1}, \theta_{2}\right)$ that gets loansshrinks as the relative efficiency of the financial sector increases (i.e., as $z / X$ increases). Moreover, this "shrinkage" is associated with increases in the average efficiency of the funded firms;

(ii) as the efficiency of the financial intermediaries increase, some low-return firms fail to obtain funding, while high-return firms receive larger loans. This increases output and measured TFP; and

(iii) increases in financial intermediary efficiency result in higher wages.

\section{Quantitative Results}

Greenwood, Sanchez, and Wang consider alternative measures of intermediation costs (interest rate spreads, the capital-to-output ratio, or overhead costs) and calibrate the model using U.S. data on firm size distribution and output per worker. Then they use the model to ask some counterfactual questions about the United Statesa mature economy in which increases in productivity in finance match overall increases in productivity-and Taiwan-a developing country that has experienced a significant increase in the relative productivity of its financial sector. They find that

(i) in the United States, about 30 percent of the growth in output per capita in the 1974-2004 period (from $\$ 22,352$ to $\$ 41,208)$ can be attributed to productivity improvements in the financial sector, $z$. Stated differently, had the level of productivity of financial intermediaries remained at its 1974 level, output per capita would have grown from $\$ 22,352$ to $\$ 33,656$. The difference is accounted for by the banking sector; and

(ii) in Taiwan, over the same period about 50 percent of the increase in output was due to improvements in $z$.

Greenwood, Sanchez, and Wang also use the model to understand the contribution of changes in the efficiency of finance on the cross-sectional distribution of output levels. To this end, they assume that the model holds; in addition, with data on interest rate spreads and output per capita, they estimate, for each country $j$, the levels of aggregate productivity, $x^{j}$, and financial sector productivity, $z^{j}$, that are consistent with the evidence. Since there is no obvious real-world ana$\log$ of the parameter $z$, they regress the value of $z^{j}$ for country $j$ on a measure of financial develop- 
ment (the ratio of private credit to gross domestic product [GDP]) and find that the correlation is high. This suggests that their identification procedure captures actual changes in efficiency.

With a parameterized model for a sample of over 40 countries, they find that the United States has the highest level of productivity outside the financial sector (i.e., the highest level of $x^{j}$ ), while Luxembourg has the highest level of financial sector efficiency (highest level of $z^{j}$ ). Then they ask the following question: "By how much would the output per capita in country $j$ increase if instead of its own (estimated) value of the efficiency of the financial sector, $z^{j}$, it had the level of financial efficiency enjoyed by Luxembourg?" Their findings include the following:

(i) World output would rise by 65 percent by moving all countries to the best financial practices.

(ii) Dispersion in cross-country output would fall by about 19 percentage points, from 77 percent to 58 percent.

(iii) Measured increases in world TFP would exceed 17 percent.

(iv) The countries that would benefit the most from this switch would see increases in output per capita of over 130 percent. Turkey, Uganda, Brazil, and Nigeria are in this category.

(v) The countries that would benefit the least would still experience significant increases in output that exceed 10 percent. This group includes New Zealand, Finland, Austria, and Ireland.

(vi) With no technological change in the financial sector, U.S. GDP would have grown at an annual rate of 1.4 percent instead of the observed 2.0 percent rate.

A careful analysis of the robustness of these results to alternative measures of intermediation costs is provided in the paper.

The paper also identifies the mechanism through which changes in the efficiency of the financial sector affect output. Greenwood, Sanchez, and Wang define the degree of distortion as the average value of the excess expected return over the cost of capital. High values of this indicator are associated with low investment and a source of inefficiency that has the flavor of "money left on the table": Some projects with high expected returns are not financed (and hence never implemented). Their findings include the following:

(i) The average distortion level ranges from a high of 49.8 percent (Uganda) to a low of 4.6 percent (Luxembourg).

(ii) The coefficient of variation across plants in a country can be high; it ranges from 32.7 percent (Uganda) to 1.94 percent (Luxembourg). This dispersion corresponds to differences across firms in the shadow price of capital, which implies that, relative to the first best, the country is in the interior of its production possibilities frontier.

(iii) The average (world) distortion level is 23.4 percent, with an average coefficient of variation of 14.6 percent. If all countries adopted Luxembourg's financial efficiency, the mean distortion drops to 2.6 percent and the average standard deviation to 1.1 percent, a very significant decrease.

The authors discuss alternative identification strategies, including the role of internal finance and robustness checks for the specification of the production function (constant elasticity of substitution instead of Cobb-Douglas), as well as unmeasured investment in intangible capital. They find that, in all cases, the differences in productivity of the financial intermediary sector account for a significant fraction of the differences in output per capita. Moreover, policies that result in increases in that productivity relative to overall productivity can have large effects on output.

\section{Conclusion}

Greenwood, Sanchez, and Wang find that finance matters for productivity and that changes in the efficiency of monitoring - a key function of financial intermediaries-can have a large impact on output. For policymakers the model 
illustrates the dangers of adopting policies that, in some sense, result in lower levels of efficiency in the financial sector, as well as the benefits associated with promoting the adoption of best practices.

\section{FINANCE AND MISALLOCATION: EVIDENCE FROM PLANT-LEVEL DATA}

Midrigan and Xu study the theoretical and quantitative effects of capital market imperfections on measured aggregate TFP. The imperfections take the form of a borrowing limit that depends on a firm's asset position. The model is rich enough to match a large number of moments of the distribution of the output growth rate of individual firms; the major finding is that financial repression does not have a large impact on measured TFP.

\section{No Entry and No Exit}

Midrigan and Xu study two different versions of their basic economy. In the first, all individuals must operate a technology (i.e., they are entrepreneurs) and there is a fixed supply of labor. In the second model, individuals can choose to be either entrepreneurs or workers, depending on their managerial skills.

The problem faced by an entrepreneur who chooses investment, savings, and consumption to maximize expected utility is

$$
\max E\left[\sum_{t=0}^{\infty} \beta^{t} U\left(C_{i t}\right)\right]
$$

subject to

$$
\begin{aligned}
& Y_{i t}=A_{i t}\left(L_{i t}^{\alpha} K_{i t}^{1-\alpha}\right)^{\eta}, \\
& W L_{i t}+K_{i t} \leq \lambda B_{i t}, \\
& C_{i t}+B_{i t+1}=Y_{i t}+(1-\delta) K_{i t}+(1+r)\left(B_{i t}-W L_{i t}-K_{i t}\right) .
\end{aligned}
$$

The first constraint is simply the production function, and $A_{i t}$ is the specific technology shock that follows some exogenous stochastic process. The second constraint is the financing constraint. It says that the expenditure on inputs-labor input $W L_{i t}$ and capital input $K_{i t}$-cannot exceed a multiple $\lambda$ of previous-period saving, $B_{i t}$. In this formulation, $\lambda=1$ corresponds to no borrowing: All expenditures must be financed using previous saving, while $\lambda=\infty$ captures perfect capital markets.

The optimal decision rules in this economy are

$$
\begin{aligned}
& F_{L}\left(L_{i t}, K_{i t}\right)=\left(1+\tilde{r}_{i t}\right) W, \\
& F_{K}\left(L_{i t}, K_{i t}\right)=\tilde{r}_{i t}+\delta,
\end{aligned}
$$

where

$$
\tilde{r}_{i t}=r+\mu_{i t},
$$

where $\mu_{i t}$ is the shadow value (Lagrange multiplier) of the financing constraint. Thus, in this model, the financing constraint effectively implies that different firms face different effective prices for inputs and, hence, that the economy must be in the interior of the production possibilities set. Improvements in the environment that decrease the financing constraint (i.e., that lower the Lagrange multiplier, $\mu_{i t}$ ) reduce the cross-sectional dispersion of input prices and, in principle, will bring the economy closer to the frontier.

Midrigan and $\mathrm{Xu}$ argue that the key driver of inefficiency in this setting is the standard deviation of the specific productivity shock, $A_{i t}$. The larger the variability, the greater the need of external sources to finance expansion and, hence, the more important any frictions in financial markets become.

\section{Quantitative Results}

Midrigan and $\mathrm{Xu}$ use data from a large dataset of firms in Korea and Colombia to estimate the parameters of the model. The key stochastic process is the individual productivity level, $A_{i t}$. They require that the estimated process be such that the model's predictions for the distribution of growth rates of individual firms match the data. Their major finding is that if they force the model to account for the skewness of growth rates, individual productivity processes do not vary much. This, in turn, implies that the cost of financial imperfections is not very large. To see this, consider the extreme case of a constant level of $A_{i t}$. In this scenario, perhaps after some initial period, 
firms can accumulate enough assets to purchase the optimal level of inputs and, hence, financial repression cannot have any lasting effects.

Given the estimated process for individual productivity, Midrigan and Xu pick the parameter $\lambda$ to match the debt-to-GDP ratio for Korea, Colombia, and a country such as the United States. They find that financial restrictions cannot account for the large estimated differences in TFP. To be precise, they estimate that U.S. TFP is 1.3 percent lower than it would have been without frictions, while in Korea-which has a relatively developed financial system-the loss is 3.6 percent, and in Colombia-which has more restrictions on financial intermediation-the loss is 5.2 percent. Since standard estimates imply that the TFP gap between poor countries and the United States is about 60 percent, the model implies that imperfect capital markets explain only 4 percent of that 60 percent.

\section{Entry and Exit}

In a second version of the basic model, Midrigan and Xu allow for entry and exit. They assume that there is some exogenous "death rate" (and a similar birth rate) and that individuals can choose, in every period, whether to be an entrepreneur or a worker. Thus, the one-period profit of an entrepreneur is

$$
\begin{aligned}
& \pi\left(B_{i t}, A_{i t}\right)=\max _{K, L} A_{i t} F(L, K) \\
& -(1+r) W L-(r+\delta) K,
\end{aligned}
$$

subject to

$$
W L+K \leq \lambda B_{i t} .
$$

The individual-agent problem is then

$$
\max E\left[\sum_{t=0}^{\infty} \beta^{t} U\left(C_{i t}\right)\right]
$$

subject to

$$
C_{i t}+B_{i t+1}=(1+r) B_{i t}+\max \left[\pi\left(B_{i t}, A_{i t}\right), W\right],
$$

where the last term indicates that the individual will choose to be a worker if $W>\pi\left(B_{i t}, A_{i t}\right)$ and an entrepreneur otherwise.
As Midrigan and Xu note, when new potential entrepreneurs are born it is important to determine the correlation, if any, between their entrepreneurial skills, $A_{i t}$, and their endowment of saving, $B_{i t}$. In the quantitative exercise, the authors consider two possible relationships between these two variables.

In this environment, financial frictions can affect productivity along two margins. First, as in the model with no entry and no exit, capital market imperfections imply that each firm faces a potentially different shadow price of capital, which creates inefficiencies. Second, the same imperfections can influence the "identity" of the individuals who become entrepreneurs. The potential cost includes both low-productivity individuals who eventually manage a firm and high-productivity individuals who, for lack of access to credit markets, choose to become workers.

\section{Quantitative Results}

Midrigan and Xu initially assume that individuals are born with no wealth. Thus, a potentially new entrepreneur has $B_{i t}=0$ at birth. As before, the authors choose the stochastic process for productivity to match the distribution of growth rates and find that the losses associated with financial constraints are much larger than in the previous case. For the United States the loss increases from 1.3 percent to 4.4 percent, for Korea from 3.6 percent to 10.6 percent, and for Colombia from 5.2 percent to 13.1 percent. Even though these estimates fall short of explaining the bulk of estimated differences, they suggest that capital market imperfections can have a significant impact on output. Interestingly, almost all the losses correspond to misallocation of inputs across firms and very few to misallocation of entrants into entrepreneurship.

One source of inefficiency in this case is the binding constraint on new high-productivity firms. In the absence of financing constraints, these firms would be "born large." However, the lack of access to credit prevents them from reaching a high scale initially. This loss of potential output reduces measured TFP. However, the counterpart of this scenario is that these productive but "asset-poor" firms grow very rapidly: 
They start small but, since they are very productive, they grow fast. When $B_{i t}=0$, the model grossly overpredicts the growth rate of young firms and, hence, this is not a good identification assumption.

As an alternative, Midrigan and $\mathrm{Xu}$ assume that initial wealth is positively related to the potential demand for inputs. They justify this assumption as a proxy for the existence of venture capitalists who can obtain a signal about $A_{i t}$ and provide start-up funds to the entrepreneur. They choose the correlation to match the growth rate of small firms. With this new parameterization they find that the loss of TFP is very similar to that of the model with no entry and no exit.

\section{Conclusion}

In a dynamic model of entrepreneurship with the requirement that the endogenous distribution of the growth rates of individual firms' output and the aggregate debt-to-GDP ratio must match the data, the major finding is that capital market imperfections can explain only a small fraction of the measured differences in TFP between rich and financially developed economies and poorand typically financially constrained-economies.

\section{MIDDLEMEN IN LIMIT-ORDER MARKETS}

Jovanovic and Menkveld study the allocative efficiency implications of financial intermediaries. They develop a series of theoretical models that are useful in understanding the role of a special type of financial intermediary: middlemen. They model middlemen as reducing frictions since they have access to better information than buyers and sellers in asset markets. They show that (i) the introduction of middlemen can either improve or reduce welfare (efficiency) and (ii) the outcome depends on the information structure. When adverse selection is not important, middlemen reduce efficiency, whereas in environments in which asymmetric information about common values creates selection problems, middlemen can improve efficiency by revealing information.

The authors analyze the impact of a trading system that they view as facilitating the intro- duction of middlemen. Their findings are mixed. Consistent with their theory, middlemen reduce bid-ask spreads but their introduction decreases trading volume. The welfare consequences of this experiment are ambiguous and more work in this area is necessary.

\section{The Model}

Jovanovic and Menkveld study a classic asset-allocation problem: One individual-the buyer-with private valuation for the asset equal to $x+z$ can trade with another individual-the seller-with private valuation given by $y+z$. In this setting, $x$ and $y$ are independently drawn from some distribution, denoted by $F$, and their values are known only to the individual parties. On the other hand, the common component $z$ may or may not be known to both buyers and sellers. In this simple environment, first-best efficiency requires that the asset be held by whoever has the higher private valuation. Thus, if $x>y$ the seller should keep the asset, while if $x \leq y$ the asset should be transferred to the buyer.

Jovanovic and Menkveld study a sequence of environments that differ in terms of their information structure. The simplest case is one in which neither party knows the value of $z$ and there are no middlemen. Even in this case, the outcome depends on the allocation of monopoly rights.

Consider the case in which the seller "comes to the market first"; then the seller can post a bid interpreted as the price at which he or she is willing to sell the asset. Normalizing the expected value of the common component equal to zero, the seller's payoff is

$$
\Pi^{s}=\max _{p} p(1-F(p))+F(p) x .
$$

The interpretation is simple: If the price $p$ is announced, the buyer will accept the bid only if $y \geq p$, which happens with probability $1-F(p)$. Thus, in the case of a sale, the seller receives $p(1-F(p))$. If the buyer's valuation is below $p-$ an event with probability $F(p)$-the seller keeps the asset and enjoys utility $F(p) x$.

Next let us look at the opposite case: The buyer comes to the market first and posts a price 


\section{Table 1}

\section{Summary Results}

\begin{tabular}{lccc} 
Regime & No. of Trades & Welfare & Spread \\
\hline First best & $T$ & $W$ & 0 \\
No middlemen & $0.5 \times T$ & $0.94 \times W$ & 0.5 \\
Middlemen & $0.6 \times T$ & $0.85 \times W$ & 0.25
\end{tabular}

at which he or she is willing to purchase the asset. In this case, the seller's payoff is

$$
\Pi^{s}=\max (y-p) F+(p)(1-F(p)) \times 0 .
$$

What is the role of an intermediary-a middleman in financial jargon-in this market? One view, noted by Jovanovic and Menkveld, is that highfrequency trading programs have an informationprocessing advantage over individuals. Thus, one way to model this advantage is to assume that the high-frequency middleman trader knows the common value $z$. Since a middleman is just an intermediary, the authors assume that he or she has no private valuation for the good-that is, if the middleman ends up with the asset, the payoff is just $z$.

The authors study a competitive version in which there is free entry into the middleman market. This guarantees that middlemen make zero profits in equilibrium. The middleman makes a bid to the seller and then, when the buyer arrives, posts an asking price. Even though the buyer does not know the common component $z$, it can be inferred from the middleman's bid. Jovanovic and Menkveld show that the asking price (by the middleman) is

$$
p^{a}=z+u,
$$

where

$$
u=\arg \max s(1-F(s)),
$$

while the middleman's bid to the seller is

$$
p^{b}=z+\pi,
$$

where

$$
\pi=\max s(1-F(s)) .
$$

Note that in the presence of middlemen both buyers and sellers "learn" the actual value of the common component $z$ and that this property does not depend on the particular properties of the distribution of $z$.

It is natural to ask whether the presence of middlemen improves the efficiency of financial markets. To this end, the authors compute an example (although the results are much more general); the results (which can be further generalized) are summarized in Table 1.

In this version of the model, the presence of middlemen unambiguously decreases welfare. It is well known from the work of Myerson and Satterthwaite (1983) that no mechanism can attain the first-best level of welfare. In this case, when buyers and sellers are symmetrically informed about the common component of the value of the asset and there are no middlemen, the level of welfare is about 94 percent of the first best. The volume of trade is only half of what would be observed in the first best and this reveals the source of the inefficiency: There are instances in which the buyer has a higher valuation for the asset and the price announced by the seller is too high and, hence, no trade takes place. Finally, there is a significant spread (defined as the average of the prices posted by sellers and buyers) in this case. Enter the middlemen (the last row of Table 1). In this case, more trades are executed (about 60 percent of the first-best volume) and the spreads decrease (from 0.5 to 0.25 ); nevertheless, welfare is lower. Thus, the simple evidence of more competition-more volume and lower spreads-does not imply higher efficiency. The reason is simple: In some cases, middlemen fail to execute both sides of the trade and they end up holding the asset. Since their valuation is lower than either the buyer's or the seller's, this is a source of welfare losses. In this environment, the conclusion is unambiguous: Middlemen reduce welfare.

What happens when buyers and sellers are asymmetrically informed about $z$ ? In this case, it is possible to show that, in the absence of middlemen, the volume of trade converges to zero as the variance of the common component grows without bound. The intuition for this is the no- 
trade theorem of Milgrom and Stokey (1982). If the payoffs to buyers and sellers were to be renormalized by dividing by the standard deviation of the common shock-an innocuous transformation given risk neutrality - those payoffs would be as follows:

$$
\begin{aligned}
& \text { Buyer: } \frac{x}{\sigma}+z, \\
& \text { Seller: } \frac{y}{\sigma}+z .
\end{aligned}
$$

Then as $\sigma \rightarrow \infty$, the valuations converge to $z-$ that is, the valuations are common to both traders-and if the private information of the buyers and sellers is just a signal of the true $z$, the no-trade theorem implies that there will be no trade in equilibrium.

Enter the middlemen again. In this case, the middlemen act just as in the previous case. Even if the traders initially were asymmetrically informed, the bid and ask prices posted by the middleman reveal the true value of $z$. This eliminates the asymmetry of information about the common component, which alleviates the adverse selection problem. Thus, in this case the presence of middlemen increases welfare.

Jovanovic and Menkveld go on to study dynamic versions and discuss mechanism design issues, but the message of their theoretical results is fairly robust: Whether middlemen improve economic efficiency depends on the traders' information structure.

\section{Empirical Analysis}

The authors analyze the advent of middlemen by exploiting the introduction of a high-frequency, trading-friendly venue as an instrument. The equity exchange Chi-X started trading Dutch index stocks on April 16, 2007. Unlike the incumbent exchange, Euronext, it did not charge traders for limit orders (i.e., posted prices), modifications, or executions; limit orders that led to execution received a rebate. The authors use data from the first 77 trading days of 2007 and 2008 to establish the treatment effect. To control for time effects they use Belgian index stocks as the untreated sample since those stocks were trading on Euronext but not on Chi-X.
They were able to identify a trader who nets out trades between the two systems. This trader has several of the characteristics of a middleman: Trades are most active when there are changes in an aggregate index of stock values, and his trading position is zero about half the time even though volume is typically high.

Jovanovic and Menkveld find that the entry of middlemen (in this case, Chi-X) is accompanied by an increase in liquidity supply and a drop in volume. The bid-ask spread did not increase for Dutch stocks but went up by 35 percent for Belgian stocks. Thus, from the perspective of the model the introduction of middlemen decreases spreads by 35 percent. The number of trades was unaffected by the entry of middlemen but volume declined.

\section{Conclusion}

The paper shows that, theoretically, the introduction of middlemen can have an ambiguous impact on welfare. The authors find some evidence of middlemen-like trading associated with the introduction of a new trading system. They find that spreads are lower after the middlemen appear, which is consistent with their theory. However, they also find that trading volume decreases and, hence, the impact on welfare is ambiguous.

\section{FINANCIAL MARKETS AND UNEMPLOYMENT}

Monacelli, Quadrini, and Trigari consider whether changes to the availability of credit may amplify unemployment fluctuations, relative to a standard business cycle model with search and matching.

The key transmission mechanism of the paper works as follows: Higher debt reduces the periodby-period surplus produced by a firm; workers and firms bargain over this total surplus, and thus higher debt allows firms to lower wages and labor costs. This idea is motivated by results from the empirical corporate finance literature. For instance, Matsa (2010) tests the premise that collective bargaining imposes a greater threat to a firm when 
the firm maintains higher levels of excess liquidity. Firms thus have an incentive to use debt to shield their liquidity from workers during bargaining. He finds that union bargaining power leads firms to increase financial leverage in a quantitatively significant way. Similarly, Bronars and Deere (1991) find a positive correlation between leverage and the degree of unionization (which may affect the bargaining power of workers).

The mechanism linking financial frictions to unemployment fluctuations considered by these authors is fundamentally different from traditional channels wherein credit facilitates investment or provides additional resources to finance production input costs. The quantitative analysis of this paper suggests that the response of employment and unemployment to credit shocks is, in fact, statistically significant and of relevant magnitude. Hence, financial frictions may indeed amplify the impact of exogenous shocks on employment and output.

\section{The Model}

The economy is constituted by risk-neutral households, which can be either employed or unemployed. While unemployed, households can costlessly search for a job. Households save in two types of assets: shares of firms and bonds. Firms are created through the matching of a posted vacancy and a worker. The number of matches is determined by a standard matching function that depends on the number of unemployed and vacancies. Matches break with probability $\lambda$ every period. All firms are subject to a common productivity shock, which varies exogenously through time. Lending is done by competitive intermediaries who pool a large number of loans. At every period, the following events take place (in sequential order): (i) wage bargaining, (ii) financial decisions, and (iii) default.

Each firm employs one worker, and output is thus equal to aggregate productivity, $z_{t}$. Dividends are output plus the net change in debt minus the wage bill, namely,

$$
d_{t}=z_{t}-w_{t}-b_{t}+\frac{b_{t+1}}{R}
$$

where $R$ is the interest rate charged on debt. Firms maximize the expected discounted value of dividends. Firms know wages are determined by Nash bargaining. More important, firms understand that debt levels, $b_{t}$, affect the outcome of the bargaining process, and take this into account when choosing their optimal debt levels. If $w_{t}=g_{t}\left(b_{t}\right)$, a firm's problem can be summarized by

$$
\begin{aligned}
& J_{t}\left(b_{t}\right)=\max _{b_{t+1}}\left\{z_{t}-g_{t}\left(b_{t}\right)-b_{t}+\frac{b_{t+1}}{R}+\beta(1-\lambda) E_{t} J_{t+1}\left(b_{t+1}\right)\right\} \\
& \text { s.t. } \\
& \varphi_{t} \beta E_{t} J_{t+1}\left(b_{t+1}\right) \geq \frac{b_{t+1}}{1+r} .
\end{aligned}
$$

The constraint of the firm's problem is the limited participation constraint. It states that the amount of debt the firm can undertake cannot be larger than a fraction of the value of the firm. The firm's credit limit is affected by an exogenous factor $\phi_{t}$; changes in its value are called credit shocks.

Observe that the additive nature of the firm's objective implies that new debt does not depend on current wages or current debt. Therefore, all firms will choose to carry forward the same level of debt. This is analytically very convenient since there is no need to keep track of the firm's distribution of debt holdings.

Since agents are risk neutral, the interest rate is constant and given by $r=1 / \beta-1$. The interest on corporate bonds takes into account that repayment occurs with probability $\lambda$. As markets are competitive, $R(1-\lambda)=1+r$.

Firms considering entry must pay a fixed entry cost. Production starts one period after entry, and thus no labor costs are incurred on entry. In equilibrium, firms will enter the market until the entry cost is equal to the value of posting a vacancy.

An important feature of the model that simplifies the bargaining problem is that the value of participation for workers is not affected by capital income. This can be done because the impact of changes in the dividend of an individual firm is negligible for an individual worker. Hence, the current payoff of being employed is the wage. The current payoff of being unemployed is an exogenously given unemployment benefit, $a$. The overall return for the household is 


$$
\hat{H}\left(b_{t}, w_{t}\right)=w_{t}+\beta E_{t}\left[(1-\lambda) H_{t+1}\left(b_{t+1}\right)+\lambda U_{t+1}\right],
$$

where the value of being employed is

$$
H_{t}\left(b_{t}\right)=g_{t}\left(b_{t}\right)+\beta E_{t}\left[(1-\lambda) H_{t+1}\left(b_{t+1}\right)+\lambda U_{t+1}\right] .
$$

In turn, the value of being unemployed, given that the probability of finding a job is $p_{t}$, is recursively defined by

$$
U_{t}=a+\beta E_{t}\left[p_{t} H_{t+1}\left(B_{t+1}\right)+\left(1-p_{t}\right) U_{t+1}\right] .
$$

As is common in this type of bargaining problems, the wage is set so that the firm and the household split the net surplus of the match,

$$
\begin{aligned}
& S_{t}\left(b_{t}\right)=z_{t}-a-b_{t}+\frac{b_{t+1}}{R} \\
& +\beta E\left[\left(1-\lambda-p_{t} \eta\right) S_{t+1}\left(b_{t+1}\right)\right] .
\end{aligned}
$$

Workers will thus capture a fraction $\eta$ of this surplus.

\section{Results}

The main theoretical finding is that firms choose to carry as much debt as the constraint allows, as long as workers have strictly positive bargaining power. The rationale is as follows: If the firm increases its debt by one unit, it can pay the present value of this amount in dividends today; however, the effective cost of repayment is lower than one. Repayment is made only with probability $1-\lambda$, and, more importantly, a higher level of debt reduces the part of the surplus that eventually goes to the worker.

The response of the model to a positive productivity shock $z_{t}$ is as follows: Higher productivity generates an employment expansion. Financial frictions amplify the effects of this shock because higher productivity also increases the value of the firm-and thus the amount it can borrowand the debt it will undertake. Ultimately, higher debt reduces the cost of labor, which motivates firms to expand employment further.

The quantitative analysis starts by considering a somewhat standard parameterization of the model. Impulse response analysis illustrates that the amplification of employment fluctuations that can be generated by this model is quantitatively relevant. Finally, a structural vector autoregressive approach is used. The shocks are identified using short-term restrictions derived from the theoretical model. The impact of credit shocks on employment is indeed statistically significant. Moreover, productivity shocks lead to credit expansions.

\section{Conclusion}

Monacelli and Trigari consider a new mechanism that may amplify the effect of shocks on unemployment and the business cycle. By incurring debt, firms lower the surplus available for bargaining with workers and thus lower labor costs. Firms thus maximize their debt capacity (limited by an endogenous constraint whereby creditors can recover only an exogenous fraction of the value of the firm). Productivity shocks, in addition to their standard effects on income and employment, change the value of the firm, and thus its debt capacity and labor costs. This amplification mechanism may be of interest to policymakers as a potential factor to account for the persistently high levels of unemployment in the United States since its recent recession.

\section{JOINT-SEARCH THEORY: NEW OPPORTUNITIES AND NEW FRICTIONS}

Guler, Guvenen, and Violante study the joint job-search and location problem of a household formed by a couple that perfectly pools income. Previous models assume these decisions are made by individuals acting in isolation. The framework of analysis builds on the well-known single-agent search models of McCall (1970) and Mortensen (1970), in which the unemployed receive a wage offer from an exogenous wage distribution every period. Rejecting an offer means remaining unemployed. Once an offer is accepted by an individual, he or she will be employed at the corresponding wage for the infinite future.

The key theoretical finding is that two-agent households face new opportunities and new 
frictions relative to one-agent households. New opportunities arise because one member of the couple can get income immediately without sacrificing the choice of "searching" for a better job (since the other member of the household may continue to receive offers). Further, by switching roles as better offers come along, a two-agent household may manage to climb the wage ladder even in the absence of an on-the-job search (per individual). The new frictions stem from the fact that job offers may come from different locations and couples face an additional cost when they do not live together. For certain model parameterizations, labor outcomes under joint job-search and location decisions are quantitatively very different from those of standard single-agent models.

\section{The Model}

Individuals live forever and all participate in the labor force. Time is continuous and there is no aggregate uncertainty. Single individuals maximize the expected lifetime utility from consumption. Everyone is entitled to certain consumption, $b$, when unemployed and receives wage offers at a constant rate, $a$, from a predetermined wage distribution, $F(w)$. The discount factor is $r$. In the standard single-agent case, the moment an offer is accepted income is forever fixed at such wage rate. The optimal strategy is characterized by a unique reservation wage such that any offer above such reservation level will be accepted, and rejected otherwise.

Members of a two-agent household can be in different states and are faced with different options in each. First, both members may be unemployed and choose to remain so. Alternatively, they can both accept their offers and stay with the associated wages forever. The most interesting case occurs when one member of the household is currently employed and the other is unemployed. The corresponding value functions $U$ (both unemployed), $T$ (both employed), and $\Omega$ (one employed and one unemployed) are defined as follows:

$$
\begin{aligned}
& r U=u(2 b)+2 \alpha \int \max \{\Omega(w)-U, 0\} d F(w) \\
& r T\left(w_{1}, w_{2}\right)=u\left(w_{1}+w_{2}\right) \\
& r \Omega\left(w_{1}\right)=u\left(w_{1}+b\right) \\
& +\alpha \int \max \left\{\begin{array}{l}
T\left(w_{1}, w_{2}\right)-\Omega\left(w_{1}\right), \\
\Omega\left(w_{2}\right)-\Omega\left(w_{1}\right), 0
\end{array}\right\} d F\left(w_{2}\right) .
\end{aligned}
$$

Since time is continuous, the probability of a simultaneous arrival of offers when both agents are unemployed is zero and is thus ignored in the definition of $U$. Couples with only one employed partner can do the following: The unemployed partner accepts a job offer and, simultaneously, the previously employed partner quits and starts looking for new offers (the gain of the couple is then $\Omega\left(w_{2}\right)-\Omega\left(w_{1}\right)$ ). This "breadwinner cycle" strategy is obviously not available to one-agent households.

\section{Results}

If agents are risk neutral, the symmetry of the model causes the couple to behave exactly as two independent single agents. For a joint labor search to make any difference agents must be risk averse. Risk aversion causes an individual agent within the couple to accept offers that a single-agent household would reject because accepting an offer does not prevent the couple from continuing to search. Similarly, if one partner is working, the unemployed member may reject offers that single individuals would accept. A breadwinner cycle does emerge in equilibrium. Partners alternate between who works and who searches, depending on the offers received by each. When faced with the same job offer sequence, single-agent households simply accept a job and then never quit. In the long run, the wages of both individuals in the two-agent household are higher under joint search due to the breadwinner cycle.

The authors consider modifications to the key model assumptions to understand the robustness of their results. One interesting modification allows employed agents to receive job offers (onthe-job search). If the rate of arrival of offers is the same for unemployed and employed individuals, then the model with dual earners yields the same solution as the single-agent case, even with risk- 
averse agents. The breadwinner cycle may also disappear if agents have access to risk-free borrowing and lending and face "loose" debt constraints. The basic intuition for this scenario is that borrowing effectively substitutes for the consumption smoothing provided within the two-agent household, making it irrelevant. Each partner can implement search strategies independent of the other partner's actions. Hence, they act again as in the single-agent case.

In the next step of the analysis, the authors extend the baseline model to study the problem of choosing among multiple locations. For single agents this extension is straightforward and only requires adjusting reservation wages for the cost of moving. In contrast, if the couple dislikes living in different locations, then optimal choices may be affected in important ways. First, if the cost of living apart is paid period by period, it can easily add up to more than the one-time relocation cost paid by a single agent. Joint search thus adds new frictions. Couples now face the following possible states: (i) Both can be employed in the same location (an absorbing state), or (ii) both can be employed in different locations (assumed to be another absorbing state). (iii) One partner can be employed and the other unemployed, or (iv) both can be unemployed and searching. Locations are assumed to be symmetric and thus partners will live together if one is unemployed. Couples must now account for inside and outside offers in their value functions.

In this framework, and even under risk neutrality, two-agent households may behave differently from single-agent households. First, each member of the two-agent household will be less selective than a single-agent household - that is, one individual of a couple will accept a wage offer that the same individual would reject if single because couples face a worse wage distribution than single agents since some wage configurations are only attainable living apart. Second, tied stayers (a partner who rejects an offer he or she would accept if single) and tied movers (a partner who follows the other partner even when individual calculations would dictate otherwise) can easily emerge in equilibrium. Both possibilities involve a high cost by each individual agent of a couple compared with being single. However, these choices are optimal from the perspective of their household.

The authors then consider a set of simulations to illustrate the quantitative implications of the theory. They show there are reasonable parameterizations under which the joint-search problem does yield results that are substantially different (quantitatively) from an analysis based on single agents. Specifically, if the cost of living apart is relatively high, then the unemployment rate in a two-agent job-search model can be as high as 13 percent versus 5 percent in the single-agent model with an otherwise comparable parameterization.

\section{Conclusion}

It is conceivable that members of a two-agent household make their job and location decisions jointly. Standard models abstract from this. Guler, Guvenen, and Violante develop a model in which two-agent households pool income perfectly to study the implications of this joint decision process. They provide a thorough analysis of conditions under which a couple's behavior will differ from that of both agents making choices independently. Theory shows the insurance provided by a household partnership introduces the possibility of a breadwinner cycle. If living apart represents a flow cost for each member of the couple, then this friction may cause individuals to reject offers or to abandon jobs that they would accept or keep, correspondingly, if single.

The analysis in this paper suggests important issues, such as the design of unemployment compensation or policies aimed at the participation or attachment to the labor force, may be better studied in a framework that explicitly models joint decisions within a household.

\section{EQUILIBRIUM PRICE DISPERSION AND RIGIDITY: A NEW MONETARIST APPROACH}

Head, Liu, Menzio, and Wright study why some sellers do not adjust their prices as soon as the aggregate price level changes. This "price stickiness," which appears to be a well-established 
feature of the data, plays a fundamental role in modern monetary models. In particular, it allows monetary policy to have real effects. The majority of such models either assume prices are sticky or impose an exogenous cost of changing prices.

Head et al. consider instead a framework in which firms can always adjust their prices at no cost. The model is a dynamic general equilibrium monetary version of Burdett and Judd's (1983) model. There is a single good and a continuum of identical consumers and firms. Firms post prices and households take as given a price distribution. Households can sample only a finite number of price offers.

The main message of this paper is that price dispersion may emerge in equilibrium, even without inflation. Monetary policy is neutral. Yet, the theory can match key statistical properties of prices in the U.S. data. The authors conclude that the fact that prices are sticky, per se, does not necessarily imply money is not neutral or that particular policy recommendations must be followed.

\section{The Model}

Time is discrete. As in Lagos and Wright (2005), in every period two markets open sequentially. The first is decentralized. Buyers and firms come together through a frictional matching process. Importantly, buyers are anonymous. Hence, trade can only occur with fiat money, which is supplied by the government. Households face the following possibilities: With probability $a_{0}$ they cannot buy any good in this period; with probability $a_{1}$ they can buy from exactly one firm; and with probability $a_{2}$ they are able to buy from two firms. Firms post prices. The household sees the firms and posted prices, $p$, from which it is possible to buy and must choose how much of the good to purchase, $q_{t}$. This household choice is constrained by the amount of money carried from the previous period, $m_{t}$. The corresponding value function is

$$
\begin{aligned}
& V_{t}\left(m_{t}, p\right)=\max _{q_{t}} u\left(q_{t}\right)+W_{t}\left(m_{t}-p q_{t}\right) \\
& \text { s.t. } \\
& 0 \leq p q_{t} \leq m_{t} .
\end{aligned}
$$

Here, $W$ denotes the value function of entering the second market (described below). The overall lifetime utility of households that enters this market with $m_{t}$ units of money can then be written as follows:

$$
\begin{aligned}
& U_{t}\left(m_{t}\right)=\alpha_{0} W_{t}\left(m_{t}\right)+\alpha_{1} \int V_{t}\left(p, m_{t}\right) d F_{t}(p) \\
& +\alpha_{2} \int V_{t}\left(p, m_{t}\right) d\left[1-\left(1-F_{t}(p)\right)^{2}\right] .
\end{aligned}
$$

Notice that the lowest price charged by the two firms is a random variable with distribution $1-\left[1-F_{t}(p)\right]^{2}$.

Firms post a nominal price, taking as given a buyer's money holdings and the price distribution, $F_{t}(p)$. The price to post and a production level are then chosen to maximize expected profits.

The second market is centralized and money or credit is allowed. Households work, purchase goods, and, in doing so, determine how much money they will have by the closing of this market. The associated value function is

$$
\begin{aligned}
& W_{t}\left(m_{t}\right)=\max _{h_{t}, x_{t}, m_{t+1}} v\left(x_{t}\right)-h_{t}+\beta U_{t+1}\left(m_{t+1}\right) \\
& \text { s.t. } \\
& w_{t} x_{t}+m_{t+1} \leq w_{t} h_{t}+m_{t}+D_{t}+T_{t} \\
& x_{t}, m_{t+1} \geq 0 .
\end{aligned}
$$

Here, $x_{t}$ denotes consumption, $h_{t}$ hours worked, and $w_{t}$ hourly wages. Government transfers are denoted as $T_{t}$ and firms' dividends $D_{t}$. A key assumption of the model is that preferences are quasilinear. This implies wealth effects wash out and thus all households choose to carry the same amount of money. The distribution of money is therefore degenerate.

The paper ultimately focuses on stationary monetary equilibrium whereby real money holdings, consumption, and hours worked remain constant, while prices grow at the same rate as the money supply.

\section{Results}

Profit maximization implies (i) the price distribution is continuous and (ii) its support must be an interval $\left[\underline{p}_{t}, \bar{p}_{t}\right]$ (either mass points or gaps in the support would allow an individual firm to obtain a discrete increase in profits by adjusting 
its prices by a discrete amount while keeping its customer base relatively constant). In equilibrium, firms must be indifferent to posting any price on the support of the distribution. Hence, more structure is needed to derive quantitative predictions.

Consider the set of firms whose prices lie on the intersection of the new support for prices (that results from monetary injections) and the old support for prices. The authors assume that at any given period a constant fraction $\rho$ of these firms keeps their prices fixed, while the others shift prices randomly. All firms whose prices do not belong to the new support of the price distribution shift to a random place in the new support. Formally,

$$
\begin{aligned}
& \text { If } p_{t} \geq \mu \underline{p}_{t}=\underline{p}_{t+1} \\
& \text { then } p_{t+1}^{*}\left(p_{t}\right)=\left\{\begin{array}{c}
p_{t} \text { with prob. } \rho \\
p^{\prime} \text { with prob. } 1-\rho
\end{array}\right\} . \\
& \text { If } p_{t}<\mu \underline{p}_{t}=\underline{p}_{t+1} \text { then } p_{t+1}^{*}\left(p_{t}\right)=p^{\prime} .
\end{aligned}
$$

In the above equation, an asterisk denotes equilibrium values; $\rho^{\prime}$ is sampled from a distribution compatible with stationary equilibrium whereby $F_{t+1}(p)=F_{t}^{*}(p / \mu)$. A nice feature of this pricing policy is that when $\rho$ equals 1 , the model attains the smallest number of price changes and the highest average price duration. When its value is set to 0 , firms change prices every period.

Not surprisingly, money is neutral in this model because the overall distribution of prices is perfectly flexible. However, money is not superneutral since inflation affects the nominal interest rate and thus real money holdings.

The next step in the analysis considers a calibrated version of the model. A set of specific parametric forms for costs, utility, and so on are selected, as is standard in the literature. When taking the model to the data, it is assumed that the decentralized market corresponds to the U.S. retail sector. Parameter values are chosen to match the average real interest and inflation rates of the U.S. data for 1988-2004. The empirical distribution of price changes of the retail sector and an average markup of 30 percent are also calibration targets. The model does an excellent job in matching these targets.
The authors then test the predictions of the model regarding the effects of inflation on the frequency and magnitude of price adjustments and contrast them to their empirical counterparts. Qualitatively speaking, the model is consistent with the data. Quantitatively, the model slightly overestimates the impact of inflation. The model reasonably accounts for the fraction of positive and negative price adjustments as inflation changes.

\section{Conclusion}

Head et al. show that individual sellers may optimally choose not to adjust prices as soon as the aggregate price level changes even though it is feasible and costless to do so because, in equilibrium, expected profits are equal for all possible prices a firm may post. The key friction is a market with matching where buyers can sample only a finite number of prices. Monetary policy is neutral, yet the model accounts for price facts very well. The key conclusion is that price stickiness does not necessarily imply that money is not neutral.

\section{INTERGENERATIONAL REDISTRIBUTION IN THE GREAT RECESSION}

If markets are incomplete, how does a negative productivity shock - a recession-affect the welfare of young and old individuals? This is the question investigated by Glover, Heathcote, Krueger, and Rios-Rull. The key observation is that households' portfolios vary systematically with age. In particular, older households hold a larger fraction of their wealth in the form of assets instead of human wealth (labor income). Consider then a negative shock that affects both asset returns and wages. This shock may induce older households to sell some of their assets and, ultimately, cause asset prices to fall more than wages. In this case, the welfare of the old decreases by more than that of the young. To see this, note that the young lose part of their labor income but are able to purchase assets at very low prices. Thus, there is a mechanism that compensates them for 
the loss of income. There is no similar mechanism that reduces the impact of the recession for the old. Thus, if these forces are at work, we expect that one of the effects of a recession is redistribution of income from relatively old households to relatively young ones.

\section{The Model}

Glover et al. use an overlapping-generations model. They assume that preferences of a typical individual are given by

$$
U=E\left\{\sum_{i=1}^{N}\left(\Pi_{j=1}^{i}\right) u\left(c_{i}\right) .\right.
$$

Individuals live for $N$ periods (deterministic lifetime) and it is assumed that there are $N$ cohorts alive at any given time, each of identical size.

Labor is traded in spot markets and households can transfer wealth across periods by trading shares of the representative firm. The model does not allow for capital accumulation.

Grover et al. study three versions of this economy distinguished by the portfolios that households are allowed to hold. The basic details are as follows:

- Economy A: In this economy, households can trade only shares in the risky firm. There are no safe assets (e.g., bonds).

- Economy B: In this economy, households can trade shares in the risky firm and a riskfree bond. However, they cannot choose their portfolio. It is exogenous and chosen to match the evidence for the United States.

- Economy $C$ : In this version, households can trade both assets and they can choose the composition of their portfolios. In this economy, asset prices are endogenous.

\section{Quantitative Results}

Glover et al. calibrate the model using U.S. data to get a sense of the quantitative effects of a recession. The basic idea is to apply each version (economies A-C) and pick all relevant parameters to match the observed life-cycle profile of earnings, net worth, and portfolio composition. The calibrated version also matches the ratios of (i) aggregate safe assets to aggregate net worth and (ii) aggregate net worth to aggregate (over a 10-year period) labor income. They assume that a recession is given by a 10 percent drop in aggregate productivity that lasts 10 years. Thus, the model assumes that the expected duration of a period of high productivity is 66.7 years and the average duration of a recession is 11.8 years.

The nature of the experiment is to explore the consequences of a transition from the aggregate high-productivity shock to a low-productivity shock. Since the three economies differ in terms of access to financial instruments, it is useful to report the results separately.

Economy A. For this version of the model, Glover et al. find that the stock price falls 20 percent during a recession (a period of 10 years in real time). In the post-recession period, stock prices slightly overshoot their long-run values. In terms of welfare, the consequences of a recession are monotonic in age: Older generations suffer more. The actual magnitudes for the baseline calibration amount to a 15 percent decline in consumption. For the youngest households this loss is just over 1 percent.

Economy B. In this economy, the decline in asset prices is similar to that of Economy A and, in general, asset prices move in the same direction. The price of bonds declines even more than the price of stocks and the pattern of welfare losses replicates that of the one-asset economy.

Economy C. In this economy, asset prices decline by more than in the other two economies. This reflects the fact that young households are heavily leveraged (relative to the other economies) and, hence, their wealth takes a larger hit. The resulting decline in consumption by the younger generations results in a larger decline in asset prices. In this economy, the old hold more safe assets than in the data and hence their welfare does not suffer as much when the recession hits. In terms of welfare-measured in consumptionequivalent units-the oldest generation experiences the largest decline (11.12 percent), although a much smaller decline than in economies $\mathrm{A}$ and B (around 14 to 15 percent). Moreover, the youngest generation actually is slightly better off since they can purchase assets at a much 
lower price. The welfare for all intermediate generations declines by more than in the other two economies.

\section{Conclusion}

Glover et al. analyze the distributional consequences of a large recession across different age cohorts. The model is highly stylized but, across different versions, a clear pattern emerges: The oldest generation appears to suffer the most from the recession since they must live the rest of their lives in that state. The very young are the least affected, as the majority of their lives will be spent in high-productivity times and they also benefit from the additional drop in asset prices when they are net buyers.

Even though asset markets are complete in a very narrow sense, there are no markets for intergenerational risk-sharing. From the perspective of a policymaker seeking to provide such insurance, a policy of subsidizing the old by running a deficit (issuing bonds) that will be paid off by future generations appears as an interesting policy alternative to run through this model.

\section{SOCIAL SECURITY, BENEFIT CLAIMING, AND LABOR FORCE PARTICIPATION: A QUANTITATIVE GENERAL EQUILIBRIUM APPROACH}

Imrohoroğlu and Kitao consider the quantitative implications of three alternative Social Security reforms: (i) a reduction in benefits and payroll taxes, (ii) an increase in the earliest retirement age (to 64 from 62), and (iii) an increase in the normal retirement age (to 68 from 66). A key motivation for this study is addressing the forecasted shortfall in the Social Security system. (According to the "2009 OASDI Trustees Report" of the Social Security Administration, either a large reduction in benefits or an increase in taxes may be required to prevent such a shortfall.) The framework of this analysis is a large-scale overlapping-generations model with incomplete insurance markets, endogenous savings, and a social security system similar to that of the United States. The model also includes health shocks, which are known to have important implications for precautionary savings and labor decisions. In contrast to previous studies within this branch of the literature, the model allows for endogenous decisions in both benefit claiming and labor force participation, which are at the core of the reforms considered by the authors.

A carefully calibrated version of the model suggests reforms (i) and (iii) (reducing benefits and payroll taxes and increasing the normal retirement age) have the largest impact. These reforms make agents save and work more to obtain better self-insurance, and the social security budget improves significantly. Reform (ii) (increasing the earliest retirement age) has a modest impact since the savings obtained from early retirees are compensated by higher expenditures at later ages.

\section{The Model}

The economy is populated by overlapping generations of individuals who live up to J periods. Their life span in uncertain. The population grows at a constant rate. Each individual is subject to a health status shock (driven by a Markov process that depends on age). The probability of living one more year is a function of the health status. Individuals start with no assets. Each individual has one unit of time per period that can be used in market or leisure activities. Agents may save in a risk-free asset but borrowing is not allowed. There is an exogenously given age-specific productivity profile that affects effective hours available for each activity. Agents face an idiosyncratic labor productivity shock every period. Finally, each individual is subject to idiosyncratic health expenditure shocks, and the distribution of these shocks depends on the health status of the individual. Health expenditure shocks are partially insured because of the presence of private health insurance. Each agent may or may not have access to private (employer-provided) health insurance. Access is determined in the first period of life and remains fixed into the infinite future. All of the elderly have access to government-provided health insurance (Medicare). Health insurance programs pay a fraction of gross expenditures 
and charge a premium. In equilibrium, premiums are such that health insurance programs are actuarially fair.

The government operates a pay-as-you-go pension system. The details of the system are carefully constructed to mimic its U.S. counterpart. Benefits are a concave function of lifetime earnings, and benefits depend on whether the agent chooses to retire early or late. Some taxes are set to match the U.S. data counterparts. The labor income tax rate is set to balance the government budget.

\section{Results}

The model is calibrated to match data from the Medical Expenditure Panel Survey (MEPS), which includes self-reported health status and medical expenditure data. Age-dependent labor productivity is from Hansen (1993), while the idiosyncratic component is based on the estimates by Heathcote, Storeslettern, and Violante (2008), whose aim is to match the observed U.S. labor income inequality. The calibrated version of the model matches the targeted U.S. data well. This suggests that the model may be a reasonable instrument to perform quantitative counterfactual experiments (and to derive the possible implications of the proposed reforms to Social Security).

The first quantitative experiment assumes the social security tax and benefits are simultaneously reduced by 50 percent. The precautionary motif causes a very strong increase in savings such that aggregate capital increases by 10 percent. For instance, savings by retirement age increase by 18.8 percent. The total labor income tax declines, and thus the labor supply increases by about 3 percent. Higher wages and hours worked ultimately translate to a Social Security budget surplus of about 0.3 percent of GDP.

The second policy considered by the authors, which raises the earliest retirement age by two years, has small implications on aggregate macro variables. Furthermore, despite the government savings from not paying benefits to individuals 62 and 63 years of age, their benefits at a later age are also higher and offset savings.
The final experiment, which increases the normal retirement age by two years, has important quantitative implications. Old-age participation increases, more individuals postpone claiming their benefits and, as a result, the Social Security deficit becomes a surplus of 1.32 percent of GDP. The aggregate capital stock and assets at retirement age increase modestly (2.4 percent and 5.5 percent), relative to the first policy reform.

The last part of the paper evaluates the implications of some modifications to the theoretical framework. One extension of considerable interest introduces forecasted changes in demographic structure into the model (the benchmark experiment takes the current demographic structure as given into the infinite future). Of course, this results in an even more serious deficit for the system absent any reform. The first and last policy reforms have quantitatively similar implications, and both turn deficits into surpluses for the Social Security system.

\section{Conclusion}

İmrohoroğlu and Kitao study the quantitative implications of three different proposals to reform (and improve the budget of) the Social Security system. This is done within a framework of a very detailed social security system that mimics the main features of the U.S. system. Either a reduction in benefits and payroll taxes or an increase in the normal retirement age will create a system surplus. In the first case, this occurs because of large increases in precautionary savings and hours worked. In the second case, it is due to the higher old-age labor participation and a modest increase in savings. Increasing the earliest retirement age, in contrast, results in current savings that are essentially canceled by later (and higher) benefit claims and thus has negligible effects on the Social Security budget. 


\section{REFERENCES}

Bronars, Stephen G. and Deere, Donald R. "The Threat of Unionization, the Use of Debt, and the Preservation of Shareholder Wealth.” Quarterly Journal of Economics, February 1991, 106(1), pp. 231-54.

Burdett, Kenneth and Judd, Kenneth L. "Equilibrium Price Dispersion.” Econometrica, July 1983, 51(4), pp. 955-69.

Glover, Andrew; Heathcote, Jonathan; Krueger, Dirk and Ríos-Rull, José-Víctor. "Intergenerational Redistribution in the Great Recession.” Presented at the 35th Annual Economic Policy Conference, Federal Reserve Bank of St. Louis, October 21-22, 2010; http://research.stlouisfed.org/conferences/policyconf/papers2010/krueger.pdf.

Greenwood, Jeremy; Sanchez, Juan M. and Wang, Cheng. "Quantifying the Impact of Financial Development on Economic Development." Presented at the 35th Annual Economic Policy Conference, Federal Reserve Bank of St. Louis, October 21-22, 2010;

http://research.stlouisfed.org/conferences/policyconf/papers2010/greenwood.pdf.

Guler, Bulent; Guvenen, Fatih and Violante, Giovanni L. "Joint-Search Theory: New Opportunities and New Frictions.” Presented at the 35th Annual Economic Policy Conference, Federal Reserve Bank of St. Louis, October 21-22, 2010; http://research.stlouisfed.org/conferences/policyconf/papers2010/guvenen.pdf.

Hansen, G.D. "The Cyclical and Secular Behaviour of the Labour Input: Comparing Efficiency Units and Hours Worked.” Journal of Applied Econometrics, January-March 1993, 8(1), pp. 71-80.

Head, Allen; Liu, Lucy Q.; Menzio, Guido and Wright, Randall. "Equilibrium Price Dispersion and Ridigity: A New Monetarist Approach." Presented at the 35th Annual Economic Policy Conference, Federal Reserve Bank of St. Louis, October 21-22, 2010;

http://research.stlouisfed.org/conferences/policyconf/papers2010/menzio.pdf.

Heathcote, Jonathan; Storesletten, Kjetil and Violante, Giovanni L. "The Macroeconomic Implications of Rising Wage Inequality in the United States.” NBER Working Paper No. 14052, National Bureau of Economic Research, June 2008; www.nber.org/papers/w14052.pdf.

İmrohoroğlu, Selhattin and Kitao, Sagiri. "Social Security, Benefit Claiming, and Labor Force Participation: A Quantitative General Equilibrium Approach.” Presented at the 35th Annual Economic Policy Conference, Federal Reserve Bank of St. Louis, October 21-22, 2010; http://research.stlouisfed.org/conferences/policyconf/papers2010/imrohoroglu.pdf.

Jovanovic, Boyan and Menkveld, Albert J. "Middlemen in Limit-Order Markets.” Presented at the 35th Annual Economic Policy Conference, Federal Reserve Bank of St. Louis, October 21-22, 2010; http://research.stlouisfed.org/conferences/policyconf/papers2010/jovanovic.pdf.

Lagos, Ricardo and Wright, Randall. "A Unified Framework for Monetary Theory and Policy Analysis.” Journal of Political Economy, June 2005, 113(3), pp. 463-84.

Matsa, David A. "Capital Structure as a Strategic Variable: Evidence from Collective Bargaining." Journal of Finance, June 2010, 65(3), pp. 1197-232.

McCall, John J. "Economics of Information and Job Search.” Quarterly Journal of Economic Theory, February 1970, 84(1), pp. 113-26. 
Midrigan, Virgiliu and Xu, Daniel Y. "Finance and Misallocation: Evidence from Plant-Level Data." Presented at the 35th Annual Economic Policy Conference, Federal Reserve Bank of St. Louis, October 21-22, 2010; http://research.stlouisfed.org/conferences/policyconf/papers2010/midrigan.pdf.

Milgrom, Paul and Stokey, Nancy L. "Information, Trade and Common Knowledge.” Journal of Economic Theory, February 1982, 26(1), pp. 17-27.

Monacelli, Tommaso; Quadrini, Vincenzo and Trigari, Antonella. "Financial Markets and Unemployment." Presented at the 35th Annual Economic Policy Conference, Federal Reserve Bank of St. Louis, October 21-22, 2010; http://research.stlouisfed.org/conferences/policyconf/papers2010/quadrini.pdf.

Mortensen, Dale T. "A Theory of Wage and Employment Dynamics," in Edmund S. Phelps, Armen A. Alchian, and Charles C. Holt, eds., Microeconomic Foundations of Employment and Inflation Theory. New York: W.W. Norton, 1970, pp. 167-211.

Myerson, Roger B. and Satterthwaite, Mark A. "Efficient Mechanisms for Bilateral Trading." Journal of Economic Theory, April 1983, 29(2), pp. 265-81.

U.S. Social Security Administration Board of Trustees. "The 2009 Annual Report of the Board of Trustees of the Federal Old-Age and Survivors Insurance and Federal Disability Insurance Trust Funds.” May 12, 2009; www.ssa.gov/OACT/TR/2009/tr09.pdf. 